\title{
Ultrasonographic Findings of Mastitic and Normal Mammary Gland in Bitches
}

\author{
Iulia Maria BALACI ${ }^{*}$, Simona CIUPE ${ }^{1}$, A. R. POP ${ }^{1}$, Laura PARLAPAN ${ }^{1}$, Alexandra ARION ${ }^{1}$, I. VASIU ${ }^{1}$, \\ R. PURDOIU ${ }^{1}$, I. PAPUC ${ }^{1}$, I. S. GROZA ${ }^{1}$ \\ ${ }^{1}$ University of Agricultural Sciences and Veterinary Medicine, Mănăştur Street, 3-5, Cluj-Napoca, \\ Romania \\ Corresponding author: balaci_i@yahoo.com
}

Bulletin UASVM Veterinary Medicine 72(1) / 2015,

Print ISSN 1843-5270; Electronic ISSN 1843-5378

DOI:10.15835/buasvmcn-vm: 11018

\begin{abstract}
The mammary gland is very important for the health of the offspring and the mother. It is subjected to multiple pathologies, the most important being mammary tumours and mastitis. The evaluation of mammary gland in bitches is done primarily by clinical exam, but imagistic means of diagnostic became more frequently used, especially when neoplasms are involved. In this context, the aim of this study was to identify the imaging characteristic of inflamed mammary parenchyma and to test the reliability of ultrasound in evaluating canine mastitis.

This study involved 12 lactating bitches of different breed and ages included in two research groups: the first group counted in 7 animals that showed clinical signs of mastitis, while the second group had 5 clinically healthy animals, being the control group. All animals were subjected to a clinical exam, followed by an ultrasound examination and milk samples collection. The ultrasound examination was done in B mode and color Doppler using both linear and microconvex transducers at a frequency of 8Mz. Milk samples were checked for color, consistency and $\mathrm{pH}$ and were later submitted for bacteriological and bacterioscopic examinations. All data that followed from the examinations was collected and analyzed.

The ultrasound examination highlighted the existence of a characteristic architecture of the layers of healthy mammary glands in the bitch. This architecture could not be seen in any of the inflamed glands. In some cases, the normal aspect of the parenchyma could still be seen at the periphery of the affected mammary gland. The inflamed parenchyma appeared either hypoechogenic $(71.43 \%$ of cases) or hyperechogenic $(28.57 \%)$ compared to healthy tissue. In $57.14 \%$ of cases there could be seen multiple hyperechogenic septa, alternating with hypo-echogenic areas while $42.86 \%$ of cases presented acoustic artefacts. The vascularisation was increased in the affected areas with blood flow being either linear $(71.43 \%)$ or turbulent $(21.57 \%)$. All cases diagnosed with mastitis were confirmed by bacteriologic and bacterioscopic studies.

This study concluded that mammary glands in bitches can be investigated using ultrasound in grey scale B mode and color Doppler when mastitis is suspected. It offers irrefutable evidence of the inflammation of the glandular parenchyma and the spreading of the disease.
\end{abstract}

Keywords: bitch, Doppler, mastitis, ultrasound.

\section{INTRODUCTION}

The health of the mammary gland directly influences the survival and the development of the whelp, but can also cause discomfort and even death to the bitch (Khan, 2011). The health of the mammary gland is therefore very important and should be monitored both in lactation and in the state of inactivity. During the lactation period, the main problems that arise are inflammations of the parenchyma, while between lactations the main concern are neoplasms (Johnston et al., 2001; Mamont and Barber, 2006). It is also important to investigate all the mammary glands, even if the most active and with most often pathologies are the inguinal and abdominal ones (Budras et al., 1996; Done et al., 1996; Kahn, 2011).

In present days, imagistic means of evaluation of the clinical state of animals are more and more 
frequently used. When considering the mammary gland of bitches, most of the present studies concentrate on describing tumours and almost ignore other pathologies like mastitis (Bovi et al., 2007; Manion, 2006; Sorenmo et al., 2011).

The aim of this study was to identify the characteristic imaging aspects of the mammary gland inflammation in bitches and to evaluate the reliability of ultrasound examination in diagnosing mastitis in this specie. These goals wanted to increase the relevance of ultrasound use on this organ.

\section{MATERIALS AND METHODS}

The present study was made on 12 bitches of different breeds, ages and weights, which were in lactation between April 2014 and June 2014. The animals were brought to the clinic of Reproduction, Obstetrics and Gynecology of the Veterinary Faculty of Cluj-Napoca for routine exam or showing clinical signs of mastitis. All bitches underwent a general clinical examination and an examination of the mammary gland through inspection and palpation. Milk samples were also collected and checked for colour, consistency and $\mathrm{pH}$. Where mastitis was suspected, milk was sent to the Department of Infectious Diseases of the Faculty of Veterinary Medicine Cluj-Napoca for confirmation.

After the examination, they were divided in two study groups, according to the physiological state they were in. Thus, group one consisted of
7 animals and represented the group of animals with clinical signs of mastitis, while group two included 5 bitches that were clinically healthy.

All animals, after being included in the study, were examined using an ultrasound in order to observe the imagistic changes induced by the inflammation of mammary tissue. The imaging exam was conducted both with a linear and a microconvex transducer with a range from $5 \mathrm{MHz}$ to $8 \mathrm{MHz}$, both in longitudinal and transverse orientation and targeted all the mammary glands, regardless of clinical signs. Additionally, a colour Doppler examination was performed for all bitches.

All the data collected from the clinical and the imaging exam was registered in original dedicated forms and analyzed accordingly.

\section{RESULTS AND DISCUSSIONS}

Of the animals included in the first group of the study, showing clinical signs of mastitis, five were purebred and two were mixed breeds. They were all between the first and forth lactation. Two of the bitches had previous reports of mammary inflammation, while the others were in this condition for the first time. All animals had already given birth and were between the first and the fifth day of lactation. Their ages ranged between 2 and 6 years old. This study didn't prove any correlation between these epidemiological data and the incidence of mastitis.
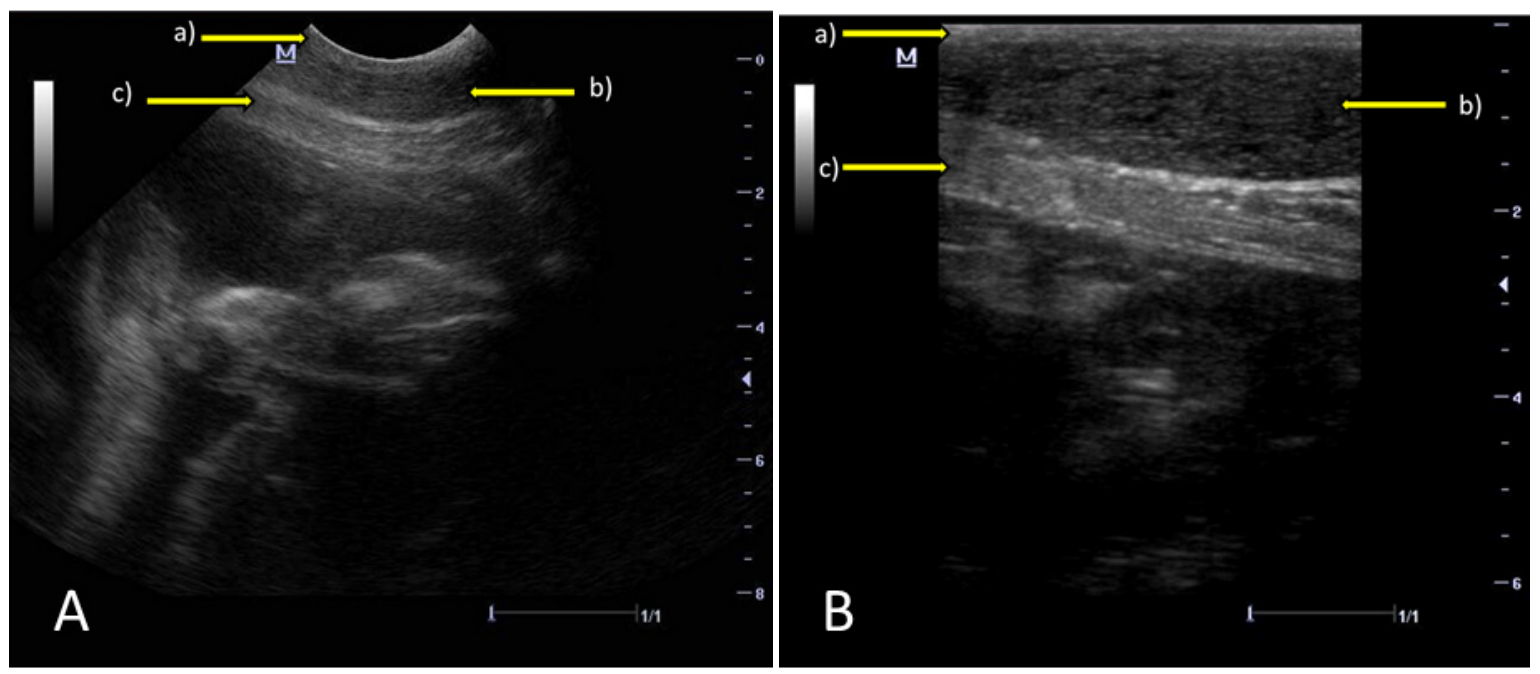

Fig. 1. Ultrasonographic aspects of an abdominal mammary gland of a healthy 5 years old Beagle, with microconvex (A) and linear (B) transducers of $8 \mathrm{MHz}$. The yellow arrows identify the specific layers of the healthy mammary gland: a) skin, b: mammary parenchyma, c) muscles. 
Three of the animals that presented clinical signs of inflammation had two mammary glands affected, while the other four had only one gland inflamed. $70 \%$ of mastitis occurred in the inguinal mammary glands, in one or both of them. The rest of $30 \%$ affected the inferior abdominal mammary gland, on the right or left side. Although we did not detect inflammation in other mammary glands, it does not mean that mastitis only occurs in the regions described in this study. Other studies report mastitis evolving in any mammary gland, but the highest incidence is in the inguinal ones, followed by the posterior abdominal ones. (Johnston et al., 2001; Momont and Barber, 2003; Trasch et al., 2007)

The animals included in the second group were aged between 2 and 7 and were in the first week of lactation after giving birth. Three animals
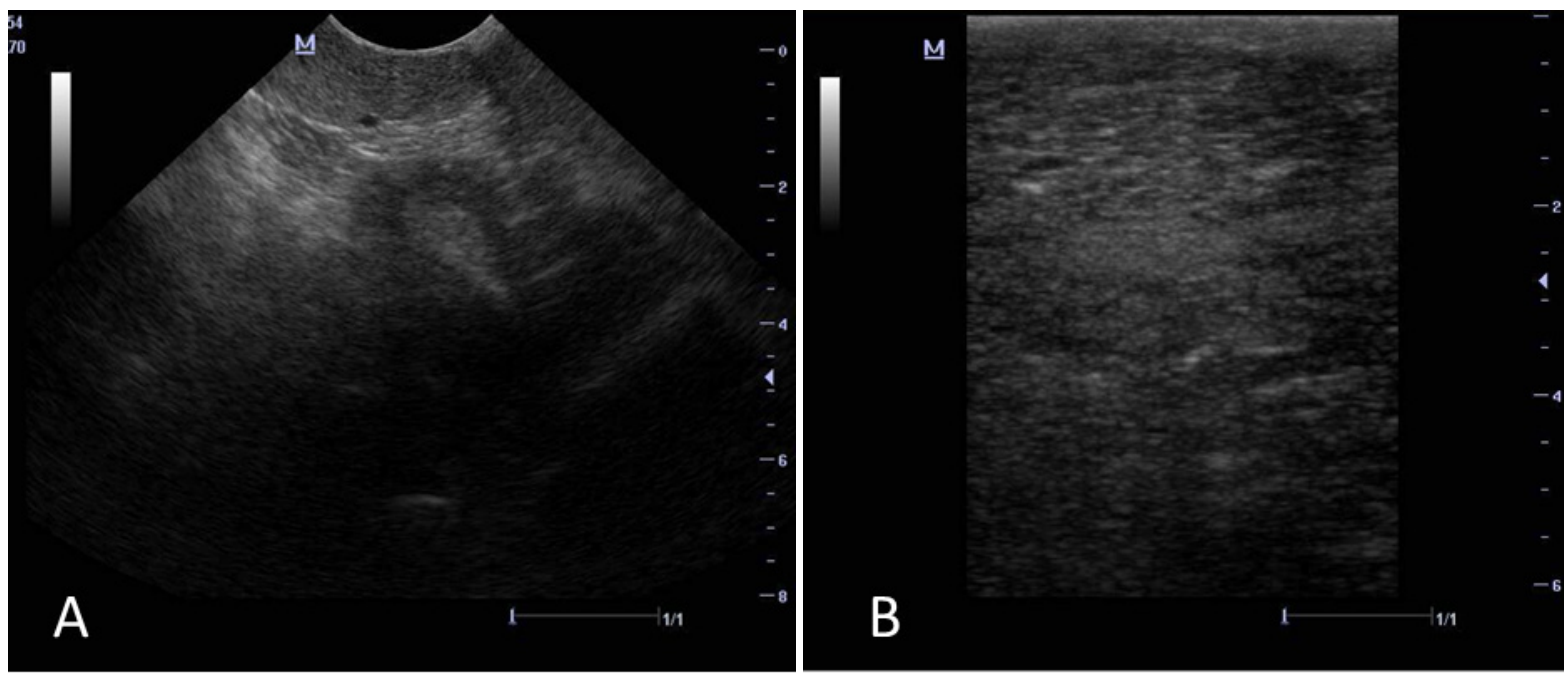

Fig. 2. Ultrasonographic aspects of an inflamed mammary gland of a 4 years old German Shepard, with microconvex (A) and linear (B) transducers of $8 \mathrm{MHz}$. Note the lack of architecture and delimitation between different tissues.

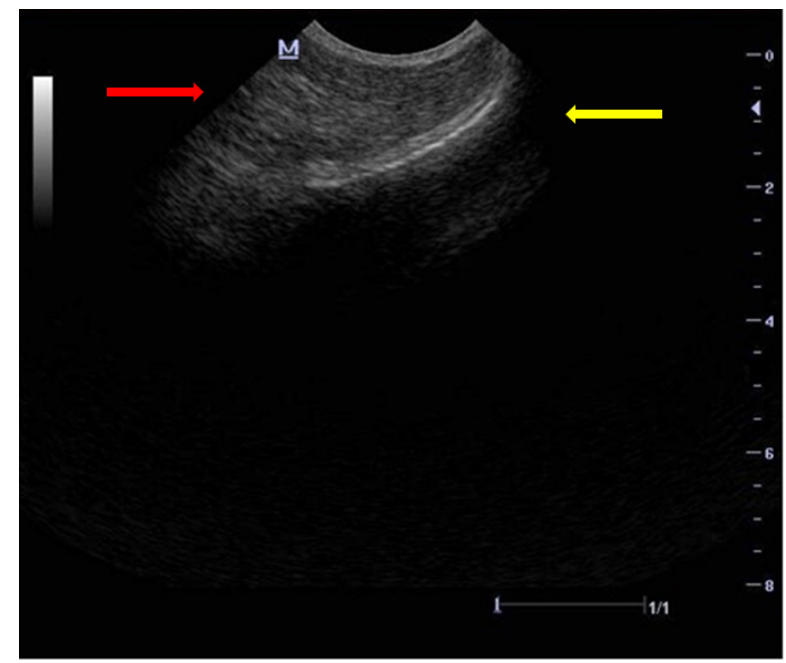

Fig. 3. Ultrasonographic aspects of the periphery of an inflamed mammary gland of 4 years old German Shepard, with a microconvex transducer of $8 \mathrm{MHz}$; the yellow arrow indicates the healthy tissue at the extremity of the gland, while the red one indicates the area closer to the middle of the inflamed mammary gland.

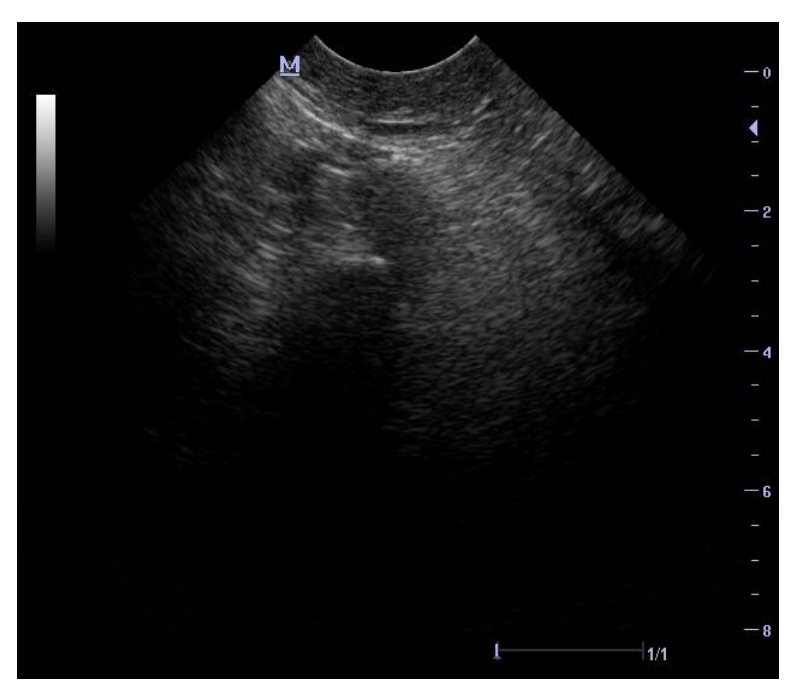

Fig. 4. Ultrasonographic aspects of an inflamed mammary gland of 3 years old Yorkshire Terrier; note the hypoechogenic aspect of the mammary parenchyma. 
were purebred, while two were mixed breeds. Two bitches were in their first lactation, while the others were in their second or third lactation.

During the imaging examination, healthy mammary glands could easily be differentiated from inflamed ones. Healthy mammary glands have a specific architecture that describes three individual layers. The upper layer is the skin, described as a clear medium echogenic and fine grained area of different width, depending on the animal and the investigated zone. The middle layer is the mammary tissue, showing a heterogenic coarse-grained structure with small areas of hyper and hypoechogenity. The most profound layer is the muscular tissue, separated from the mammary tissue by the abdominal fascia; the fascia appears as a hiperechogenic, well defined line, while the muscles appear of medium echogenity but slightly hiperechogenic compared to the parenchyma, coarse grained and heterogenous. These aspects could easily be seen both using a microconvex transducer (Fig. 1A) and a linear transducer (Fig. 1B).

These aspects are in accordance with other studies that describe the imaging aspects of canine mastitis. (Nyman et al., 2006; Thrash et al., 2007). Comparing the two transducers, we considered the linear transducer more useful, especially with large animals. The microconvex

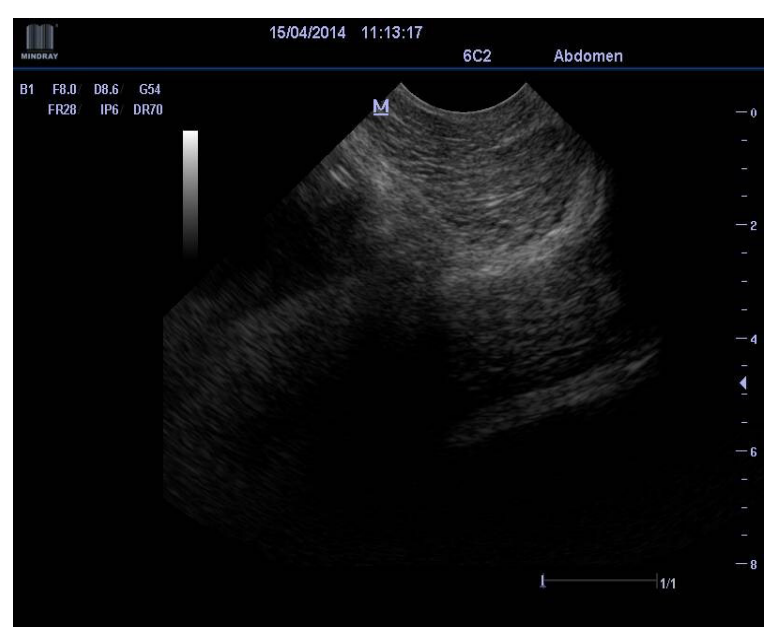

Fig. 5. Ultrasonographic aspects of an inflamed mammary gland of a 6 years old Rottweiler; note the multiple hyperechogenic septa in the parenchyma and the overall hyperechogenic aspect of the mammary gland. transducers, although it offers a larger view of the tissue, provides less information and of lower quality than the linear one.

In mammary glands that presented signs of infection, the architecture presented above could not be observed. The skin remained visible, but there was no delimitation between the mammary parenchyma and the more profound tissues of the investigated area in all the examined cases, both with the microconvex (Fig. 2A) and the linear transducers (Fig. 2B).

In some cases, the normal architecture of the mammary gland could still be seen using the ultrasound at the periphery of the gland, proving that the inflammation started in the center of the organ and speeded to the exterior (Fig. 3). This aspect is to be expected since most mammary gland infections in the bitch are ascending, having as a gateway the papillary duct that opens during suckling. (Kahn 2011; Schäfer-Somi et al., 2003)

The mammary parenchyma of the inflamed glandes appeared in all cases more heterogeneous than the healthy tissue, with numerous areas of hyper-and hypoechogenity. Theseareas hadvariable sizes (between $1 \mathrm{~mm}$ and $3 \mathrm{~mm}$ ) and distribution. In $71.43 \%$ of cases the inflamed mammary tissue was overall more hypoehcogenic than the healthy one (Fig. 4), but in $28.57 \%$ the affected area was slightly hyperechogenic (Fig. 5). Other studies described

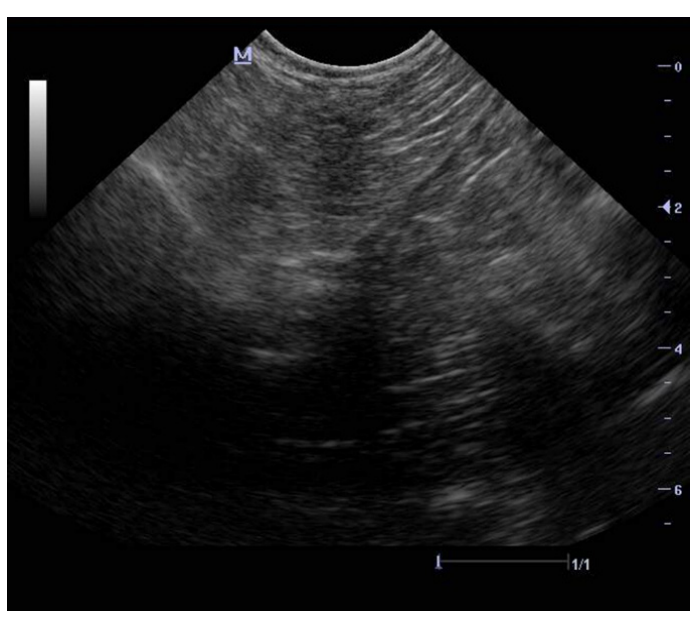

Fig. 6. Ultrasonographic aspects of inflamed mammary gland of a 4 years old German Shepard; note the multiple hyperechogenic lines in the center of the affected area and the muscular fascia that is only visible at the pheriphery of the organ as a thin hyperechogenic line. 
the inflamed zone as always being hypoechogenic compared to the healthy tissue (Trasch et al., 2007). This study did not mention in what day of lactation the exam took place, or at how many days after the onset of the clinical signs. The inflamed zone normally appears more hypoechogenic because of the infiltration and oedema that takes place in the affected area, phenomena that is generally found

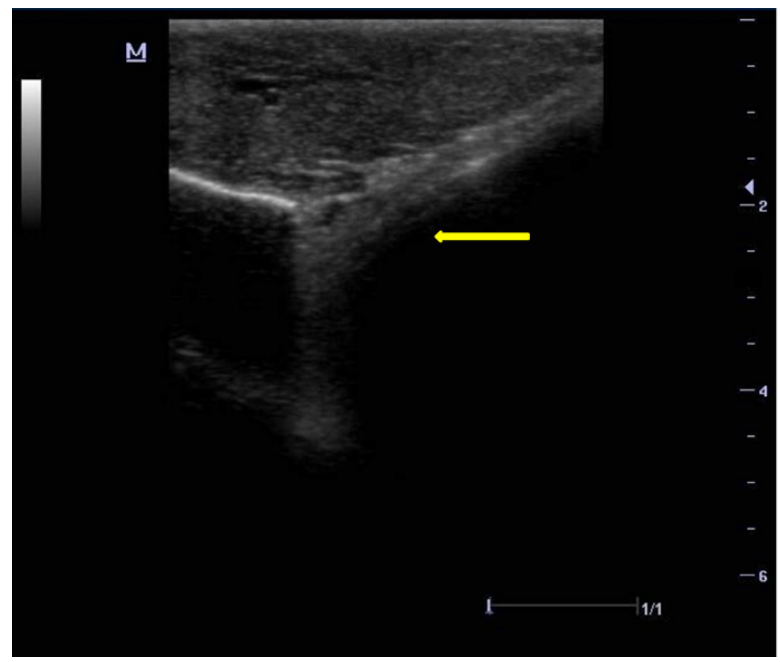

Fig. 7. Ultrasonographic aspects of an inflamed mammary gland of a 6 years old Rottweiler; note the hyperechogenic line that corresponds to the muscular fascia and ends abruptly, followed by an acoustic enhancement artefact.

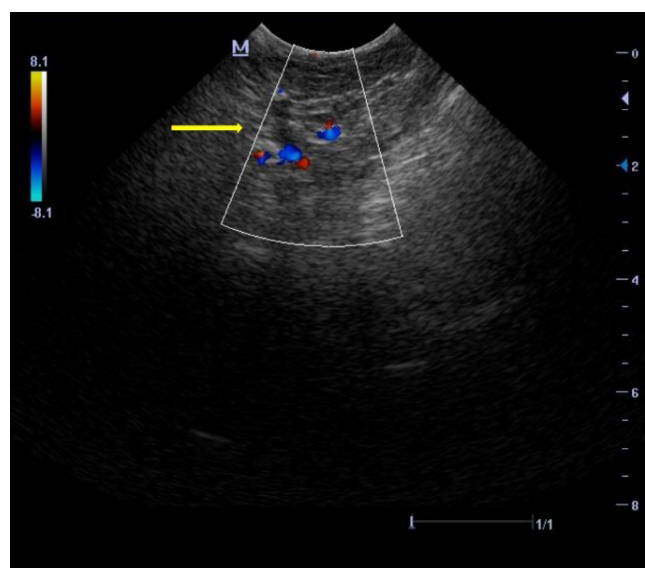

Fig. 9. Ultrasonographic B mode and color Doppler aspects of an inflamed mammary gland of a 3 years old Mix breed; note the increased blood perfusion of the parenchyma; the yellow arrow indicates the linear blood flow. in mastitis. The hyperecogenic aspect appeared in bitches that were in the third to fifth day of lactation, suggesting the evolution of a chronic inflammation that did not have very clear clinical signs at the beginning, or a flare of a pathological process that originated in the previous lactation. In ruminants, inflamed mammary gland have been

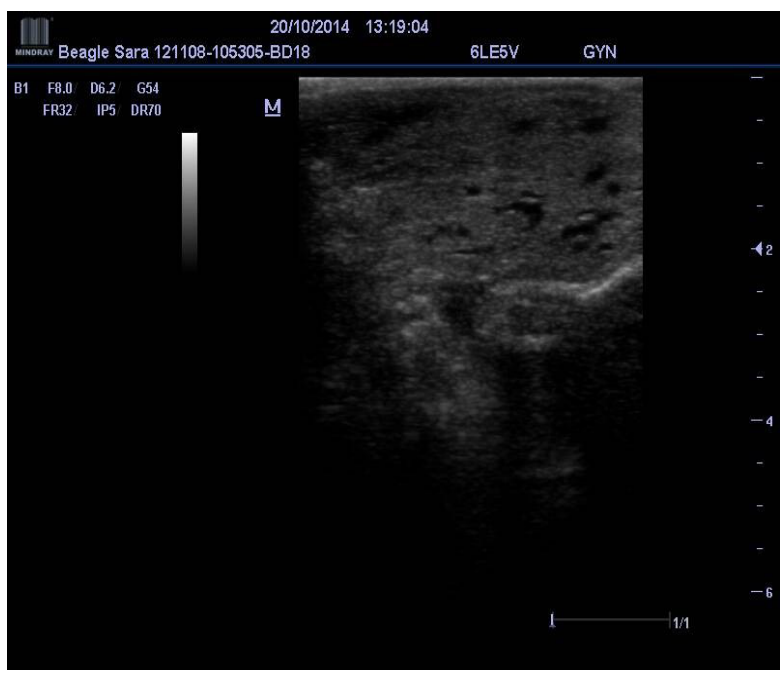

Fig. 8. Ultrasonographic aspects of an inflamed mammary gland of a 6 years old Rottweiler; note the multiple anechogenic areas present in the parenchyma, they correspond to blood vessels and milk ducts; the muscular fascia can be seen at the right extremity of the image as a hyperechogenic line.

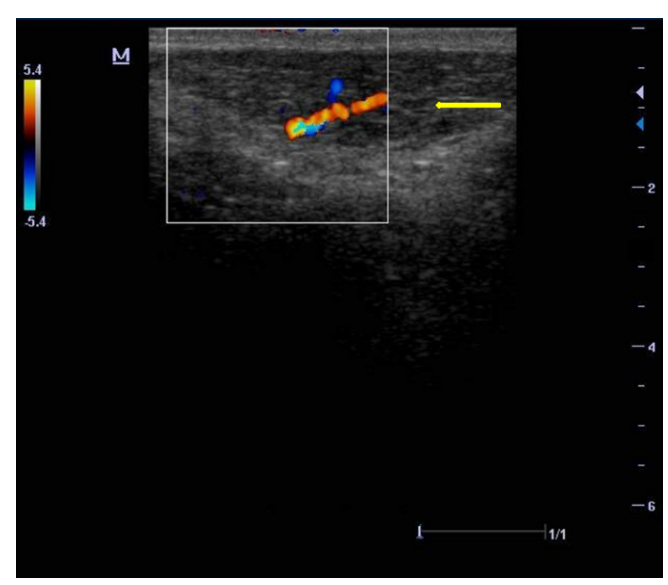

Fig. 10. Ultrasonographic B mode and color Doppler aspects of an inflamed mammary gland of 3 years old Yorkshire; the parenchyma presents few bigger vessels with turbulent blood flow, as pointed out by the yellow arrow. 
reported to become either hipo or hyperechogenic as well. (Santos et al., 2014)

In $57.14 \%$ of cases there were observed many hyperechogenic lines in the affected part of the mammary parenchyma, alternating with hypoechogenic areas. The muscular fascia appeared as a thin hyperechogenic line or could not be distinguished at all (Fig. 6).

In $42.86 \%$ of cases there were found acoustic artefacts of reverberation or acoustic enhancement (Fig. 7). These artefacts are caused by the infiltration that takes place in the affected tissue. There has also been observed an increase in the number of anechogenic areas that correspond to milk ducts or blood vessels (Figure 8). Similar aspects have been found by other studies both in bitches and in other mammals (Santos et al., 2014; Trasch et al., 2007).

The colour Doppler examination pointed out an increased blood perfusion in all examined cases. The vessels were disposed in all the parenchyma, but mostly at the periphery of the affected area (Fig. 9) and had linear (71.43\%) or turbulent (21.57\%) blood flow (Fig. 10). The milk ducts appeared anechogenic.

These signs of inflammation proved to be sufficient to put a diagnosis of mastitis using the ultrasound. Both transducers proved good, with the linear transductor giving more information than the microconvex one. Also, when there has been performed a caesarean on the white line, the tissular reaction produced determined signs of inflammation at mammary level when the microconvex transducer was used. This effect has not been present with the linear transducer.

All the diagnosed cases of mastitis were confirmed by the Infectious Diseases department after milk evaluation, while the clinically healthy ones did not have pathogenic bacteria in their milk. After the diagnosis, the animals were treated according to the antibiogram.

\section{CONCLUSIONS}

The health of the mammary gland of lactating bitches is very important for the survival and development of the pups. Inflammation of the mammary parenchyma can pose a threat both to the offspring and the mother. That is why special attention should be given to its health before and after giving birth. The ultrasound examination proved very useful in detecting mammary gland inflammations when using both a linear and a microconvex transducer at the frequency of $8 \mathrm{MHz}$. The linear transducer proved more reliable and has given more information in the studied cases. Healthy tissue can easily be differentiated from inflamed one on consideration of tissue architecture, echogenity, homogeneity, artefacts and vascularization.

Acknowledgements. This paper was published under the frame of European Social Fund, Human Resources Development Operational Programme 2007-2013, project no. POSDRU/159/1.5/ S/136893.

\section{REFERENCES}

1. Bovi J, Sharon QX, White J (2007). Comparison of three accelerated partial breast irradiation techniques: Treatment effectiveness based upon biological models. Department of Radiation Oncology, Medical College of Wisconsin, Milwaukee, WI, USA.

2. Budras KD, Frike W, Richter R (1996). Atlas der Anatomie der Hundes. Lehrbuch für Trerärzte und Studierende. Schütersche Vergsanstalt und Drukerei Gmbh \& Co, HansBöckles, Hannover.

3. Davidson AP, Baker TW (2009). Reproductive Ultrasound of the Bitch and Queen. Topics in Companion Animals Medicine 24(2):55-63.

4. Done SH, Goody PC, Evans SA, Stickland NC (1996). Color atlas of veterinary anatomy. Vol 3. Mosby-Wolfe, London.

5. Johnston SD, Kustritz MVR, Olson PNS (2001). Disorders of mammary glands of the bitch. In: Johnston SD, Kustritz MVR, Olson PNS (Eds). Canine and Feline Theriogenology. WB Saunders Company, Philadelphia, 243-256.

6. Kahn Cyntia (2011). The Merck Veterinary Manual 10th (tenth) edition, Merck Sharp \& Dohme Corp.

7. Manion Paddy (2006). Diagnostic Ultrasound in Small Animal Practice, Blackwell Science Ltd.

8. Momont H, Barber JA (2003). Mammary disorders. Root-Kustritz MV(editor). Small Animal Theriogenology. Butterworth/Heinemann, 421-446.

9. Nyman HT, Kristensen AT, Lee MH, Martinussen T, McEvoy FJ (2006). Characterization of canine superficial tumors using gray-scale B mode, color flow mapping, and spectral doppler ultrasonography-A multivariate study. Vet Radiol Ultrasound 47:192-198.

10. SantosVJC, Simplício KG, Sanchez DC, Almeida VT, TeixeiraPPM, Coutinho LN, Vicente WR (2014). Ultrassonografia convencional e Doppler em cabra com mastite gangrenosa. Arq Bras Med 66, 6.

11. Schäfer-Somi S, Spergser J, Breitenfellner J, Aurich JE (2003). Bacteriological status of canine milk and 
septicaemia in neonatal puppies--a retrospective study. J Vet Med B Infect Dis Vet Public Health 50(7):343-6.

12. Sorenmo KU, Rasotto R, Zappulli V, Goldschmidt MH (2011). Development, Anatomy, Histology, Lymphatic Drainage, Clinical Features, and Cell Differentiation
Markers of Canine Mammary Gland Neoplasms. Vet Pathol 2011 Jan 48(1):85-97. Epub 2010 Dec7.

13. Trasch K, Wehrend A, Bostedt H (2007). Ultrasonographic description of canine mastitis. Vet Radiol Ultrasound 48(6):580-4. 